\title{
STRUCTURE OF THE ENERGY BALANCE IN THE ICE SHEET-ATMOSPHERE SYSTEM AS AN INDEX OF ANTARCTIC GLACIATION
}

\section{(Abstract only)}

\author{
by \\ V. G. Aver'yanov \\ (Arctic and Antarctic Institute, Leningrad, U.S.S.R.)
}

ABSTRACT

Various methods have been used to estimate mean multi-year values of moisture, radiation, and heat exchange in the Antarctic ice sheet/atmosphere system. The major components of the balance have been determined as absolute and relative values. The net advection of moisture is taken as $100 \%$, of which $83 \%$ is deposited as accumulation on the ice sheet, and the residue in the atmosphere is $15 \%$; loss from the icesheet surface is $2 \%$. In the radiation balance, input at the top of the atmosphere is $57 \%$, absorption in the atmosphere is $43 \%$, loss due to reflected shortwave radiation is $35 \%$, and long-wave radiation from the atmosphere is $78 \%$, while net outgoing long-wave radiation from the surface is $9 \%$. The heat-budget components are:

\section{Income}

absorbed short-wave radiation

latent heat from phase change of advected moisture

\section{Loss}

outgoing long-wave radiation

heat from phase change

of atmospheric moisture

$2 \%$

The Antarctic ice sheet is a vast heat sink. Constant negative surface-radiation balance and low temperature of the ice sheet suggests that it will survive with even small amounts of precipitation. Thus the contemporary glaciation of Antarctica is rather stable.

\section{THE HEAT REGIME OF THE CENTRAL PARTS OF THE}

\section{ANTARCTIC ICE SHEET WITH CHANGING CLIMATE}

\section{(Abstract only)}

by

\author{
V. R. Barbash and I. A. Zotikov \\ (Institute of Geography, Academy of Sciences U.S.S.R., Staromonetny per. 29, Moscow 109017.
} U.S.S.R.)

\section{ABSTRACT}

The heat regime and dynamics of the Antarctic ice sheet are studied using numerical modelling for two flow lines, one of which passes Vostok station and the other Byrd station. A two-dimensional non-steady heat-transfer equation with an energy dissipation term was used. The study consists of two parts. The first is a study of velocity and temperature distributions within the glacier under steady-state conditions. The second study was performed assuming surface temperature changes intended to model palaeoclimatic changes for the last $100 \mathrm{ka}$ and al so to model future climate changes due to a possible "greenhouse" effect.
Computer numerical modelling shows that the Antarctic ice sheet retains a record of the climatic temperature minimum $18 \mathrm{ka}$ BP. Numerical modelling of the greenhouse effect assumes a temperature increasing by $10 \mathrm{deg}$ within the next $100 \mathrm{a}$; its influence increases after this even if the surface temperature then remains the same for the next $20 \mathrm{ka}$. It is shown that for the next $1 \mathrm{ka}$ the temperature wave will penetrate only a thin surface layer of the ice. Even in $20 \mathrm{ka}$ the bottom temperature of the ice sheet will still be unchanged. Small increases of ice velocity can produce ice-sheet thinning of the order of $10 \mathrm{~m} \mathrm{a}^{-1}$. 